\title{
INVESTIGATION OF GEOMETRIC AND MATERIAL EFFECTS ON CRITICAL LOAD OF THERMOPLASTIC-MATRIX COMPOSITE PLATES WITH A SQUARE HOLE UNDER IN-PLANE LOADINGS
}

\author{
Fuat Okumuş \\ Department of Mechanical Engineering \\ Gediz University,35230 \\ Çankaya,İzmir, Turkey \\ fokumus1953@hotmail.com
}

\begin{abstract}
In this study, an investigation of buckling analysis which includes geometric and material effects on critical load of thermoplastic-matrix composite plates with square hole is carried out by using finite element method (FEM). A finite element computer program is developed for finding critical loads. The composite plates $\left(\left[0^{0} / \theta^{0}\right.\right.$ ]$_{2}$ ) under transverse loading are formed by stacking four composite layers bonded symmetrically or antisymmetrically. Each layer with constant thickness is meshed into 48 elements and 228 nodes. The first-order shear deformation theory is employed in mathematical formulation. the effects on critical load by ply lamination geometry, plate thickness ratio, loading types, hole size, and material modulus ratio have been investigated. Numerical solutions are given in graphical forms.
\end{abstract}

Key words- Thermoplastic laminated plates, Plates with square hole, Finite element method.

\section{INTRODUCTION}

The fiber-reinforced thermoplastic polymer-matrix composites are laminated hybrid composites in which plies of fiber-reinforced thermoplastic polymer are bonded to plies. This type of composite can be tailored as desired and the laminate mechanical properties can also be improved by proper thermal-mechanical processes. Thermoplastic-matrix composites are presently of interest because of the improved interlaminar fracture toughness, increased impact resistance and higher solvent resistance in relation to thermoset composite systems. Moreover thermoplastic composites are easily repaired and they can be remelted for repairing the local cracks and delaminations. In recent years, applications of long fiber thermoplastic composites have increased constantly in a wide range of sectors including the automotive, construction, marine equipments and furniture industries. This type of composite has been under on intensive investigation [ 1-4 ].Many studies on the stability of elastic, isotropic plates have been made, but very little work has been done on the anisotropic plates with holes. Vanden Brink and Kamat [5] presented a finite element analysis for the isotropic and laminated composite square plates with circular holes. Applying finite element and perturbation methods, Larsson [6] investigated buckling of orthotropic compressed plates with circular holes. Using the finite element method for computing in-plane stress, Uenaya and Rewood [ 7 ] determined the shear buckling of square plates with holes by the aid of the Rayleigh-Ritz method. Chou et al.[ 8 ] reviewed the work on fibre-reinforced metal-matrix composites involving fabrication methods, mechanical 
properties, secondary working techniques and interfaces.Ananth et al. [ 9 ] investigated the application of push out test to characterize the mechanical behavior of interfaces in metallic and intermetallic matrix composites by using the finite element method and also studied the effect of different material and testing variables on the experimental data. Pitchumani et al. [10 ] used an eddy current technique for the measurement of constituent volume fractions in a three phase metal-matrix composite. The volume fractions were calculated using eddy current measurements made on a wide range of silicon carbide reinforced aluminum matrix composite extrusions.

Pomies and Carlsson [ 11 ] carried out micromechanical finite element analysis of rigidity and strength of transverse tension loaded continous fiber composites and compared their results with experimental data for dry and wet glass-epoxy, carbonepoxy composites. Zocher [ 12 ] presented numerically generated failure envolopes for several three-dimesional failure criteria and compared them with experimental data. Lin and Kuo [ 13 ] studied the effect on critical load of materials of epoxy-glass and Boronepoxy and some comparisons are also made with those in the literature. In this study, an investigation of buckling analysis which includes geometric and material effects on critical load of woven stainless steel fiber-reinforced thermoplastic-matrix laminated plates with square hole is carried out The fiber-reinforced thermoplastic symmetric or antisymmetric laminated plates having square holes are statically loaded. The ply orientations in the laminated plate are selected as $\left(0^{\circ} / 90^{\circ}\right),\left(\left[0^{\circ} / 90^{\circ}\right] 3\right),\left(\left[30^{\circ} /-\right.\right.$ $\left.\left.30^{\circ}\right]_{2}\right),\left(\left[45^{\circ} /-45^{\circ}\right]_{2}\right)$, and $\left(\left[60^{\circ} /-60^{\circ}\right]_{2}\right)$ The first-order shear deformation theory and the variation energy method are employed in the mathematical formulation and the finite element method (FEM) is used for finding critical loads. The effects on critical load by hole size, ply-lamination geometry, loading types have been investigated. The Tsai-Hill theory is used as a yield criterion.

\section{MATHEMATICAL FORMULATION}

The woven stainless steel fiber reinforced thermoplastic-matrix laminated plate of constant thickness is composed of orthotrpic layers bonded symmetrically or antisymmetrically about the middle surface of the plate. The laminated plates are loaded with simply supported and clamped plates with square hole are loaded transversely. Notch geometry and loading configuration is illustrated in Figure 1. where the middle surface of the plate coincides with the $x-y$ plane. Considering transverse shear deformations in the solution of laminated plate elements, the stress-strain relations for an orthotropic layer can be written as,

$$
\begin{aligned}
& \left\{\begin{array}{c}
\sigma_{x} \\
\sigma_{y} \\
\tau_{x y}
\end{array}\right\}=\left[\begin{array}{lll}
\overline{Q_{11}} & \overline{Q_{12}} & \overline{Q_{16}} \\
\overline{Q_{21}} & \overline{Q_{22}} & \overline{Q_{26}} \\
\overline{Q_{16}} & \overline{Q_{26}} & \overline{Q_{66}}
\end{array}\right]\left\{\begin{array}{l}
\varepsilon_{x} \\
\varepsilon_{y} \\
\gamma_{x y}
\end{array}\right\} \\
& \left\{\begin{array}{c}
\tau_{y z} \\
\tau_{x z}
\end{array}\right\}=\left[\begin{array}{ll}
\overline{Q_{44}} & \bar{Q}_{45} \\
\overline{Q_{45}} & \overline{Q_{55}}
\end{array}\right]\left\{\begin{array}{l}
\gamma_{Y Z} \\
\gamma_{X Z}
\end{array}\right\}
\end{aligned}
$$

where the transformed reduced stifness, $\overline{\mathrm{Q}}_{\mathrm{ij}}$ are given in terms of engineering constants 
of the material. According to first-order shear deformation theory, the particles of the plate, originally on a line that is normal to the undeformed middle surface, remain on a straight line during deformation, but this line is not necessarily normal to the deformed middle surface. Thus, the displacement components of a point of coordinates $\mathrm{x}, \mathrm{y}, \mathrm{z}$ for small deformation can be written as follows,

$\mathrm{u}(\mathrm{x}, \mathrm{y}, \mathrm{z})=\mathrm{u}_{\mathrm{O}}(\mathrm{x}, \mathrm{y})+\mathrm{Z} \Psi_{\mathrm{x}}(\mathrm{x}, \mathrm{y})$

$\mathrm{v}(\mathrm{x}, \mathrm{y}, \mathrm{z})=\mathrm{v}_{\mathrm{O}}(\mathrm{x}, \mathrm{y})+\mathrm{Z} \Psi_{\mathrm{y}}(\mathrm{x}, \mathrm{y})$

$\mathrm{w}(\mathrm{x}, \mathrm{y}, \mathrm{z})=\mathrm{w}(\mathrm{x}, \mathrm{y})$

where $\mathrm{u}_{\mathrm{O}}, \mathrm{v}_{\mathrm{O}}$ and $\mathrm{w}$ are the displacements of a point on the middle surface, and $\Psi_{\mathrm{x}}, \Psi_{\mathrm{y}}$ are the rotation angles of normals to the $\mathrm{y}$ and $\mathrm{x}$ axes, respectively. By using linear strain-displacement relations, bending strains are found to vary linearly through the plate thickness, whereas shear strains are assumed to be constant throughtout the thickness as,

$$
\begin{gathered}
\left\{\begin{array}{l}
\varepsilon_{x} \\
\varepsilon_{Y} \\
\varepsilon_{x y}
\end{array}\right\}=\left\{\begin{array}{c}
\frac{\partial u_{0}}{\partial x} \\
\frac{\partial v_{0}}{\partial y} \\
\frac{\partial u_{0}}{\partial y}+\frac{\partial v_{0}}{\partial x}
\end{array}\right\}+\left\{\begin{array}{c}
\frac{\partial \psi_{x}}{\partial x} \\
-\frac{\partial \psi_{y}}{\partial y} \\
\frac{\partial \psi_{x}}{\partial y}-\frac{\partial \psi_{y}}{\partial x}
\end{array}\right\} \\
\left\{\begin{array}{l}
\gamma_{y z} \\
\gamma_{x z}
\end{array}\right\}=\left|\frac{\partial w}{\partial y}-\psi_{y}\right| \\
\frac{\partial w}{\partial x}+\psi_{x} \mid
\end{gathered}
$$

In order to obtain the element equilibrium equations, the total energy of a laminated late under static loading is given as follows:

$\Pi=\mathrm{U}_{\mathrm{b}}+\mathrm{U}_{\mathrm{s}}+\mathrm{V}$

Where $U_{b}$ is the strain energy of bending, $U_{s}$ is the strain energy of shear and $V$ denotes the potential energy of external in-plane loadings $\left(\mathrm{N}_{1}, \mathrm{~N}_{2}, \mathrm{~N}_{12}\right)$. They are defined as,

$$
\begin{aligned}
& \Pi=\frac{1}{2} \int_{-h / 2}^{h / 2}\left[\int_{A}\left(\sigma_{\mathrm{x}} \varepsilon_{\mathrm{x}}+\sigma_{\mathrm{y}} \varepsilon_{\mathrm{y}}+\tau_{\mathrm{xy}} \gamma_{\mathrm{xy}}\right) \mathrm{dA}\right] \mathrm{dz}+\frac{1}{2} \int_{-h / 2}^{h / 2}\left[\int_{A}\left(\tau_{\mathrm{yz}} \gamma_{\mathrm{yz}}+\tau_{\mathrm{xz}} \gamma_{\mathrm{xz}}\right) \mathrm{dA}\right] \\
& \mathrm{dz}-\int_{A} \mathrm{WpdA}-\int_{\partial R}\left(N_{n}^{b} u_{n}^{0}+N_{s}^{b} u_{s}^{0}\right) \mathrm{ds}
\end{aligned}
$$

Where $\mathrm{dA}=\mathrm{dxdy}$ and $\mathrm{R}$ is the region of a rectangle excluding hole, and $N_{n}^{b}, N_{s}^{b}$ are the in-plane loads applied on the boundary $\partial R$. The resultant forces $\mathrm{N}_{\mathrm{x}}, \mathrm{N}_{\mathrm{y}}, \mathrm{N}_{\mathrm{xy}}$, are not constant but are functions of $x$ and $y$. The forces $\left(N_{x}, N_{y}, N_{x y}\right)$, moments $M_{x}, M_{y}$ and 
$\mathrm{M}_{\mathrm{xy}}$ and shearing forces $\mathrm{Q}_{\mathrm{x}}$ and $\mathrm{Q}_{\mathrm{y}}$ per unit length of the cross section of the laminated plate are given as,

$$
\begin{aligned}
& \left|\begin{array}{cc}
\mathrm{N}_{\mathrm{x}} & \mathrm{M}_{\mathrm{x}} \\
\mathrm{N}_{\mathrm{y}} & \mathrm{M}_{\mathrm{y}} \\
\mathrm{N}_{\mathrm{xy}} & \mathrm{M}_{\mathrm{xy}}
\end{array}\right|=\int_{-h / 2}^{h / 2}\left\{\begin{array}{c}
\sigma_{\mathrm{x}} \\
\sigma_{\mathrm{Y}} \\
\tau_{\mathrm{xy}}
\end{array}\right\}(1, \mathrm{z}) \mathrm{dz} \\
& \left\{\begin{array}{l}
Q_{x} \\
Q_{y}
\end{array}\right\}=\int_{-\frac{h}{2}}^{\frac{h}{2}}\left\{\begin{array}{l}
\tau_{x z} \\
\tau_{y z}
\end{array}\right\} d z
\end{aligned}
$$

For equilibrium, the potential energy $\Pi$ must be stationary. It is obtained so that $\delta \Pi=0$ which may be regarded as the principle of virtual displacement for the plate element [10].

\section{FINITE ELEMENT ANALYSIS}

In order to find critical loads for angle-ply laminates, nine node finite elements were employed. The symmetric or antisymmetric laminated plates are composed four layers. Each layer having geometric and loading symmetry is automatically meshed into 48 elements and 228 nodes with both simply supported or clamped boundary conditions. The stiffness matrix of the plate is obtained using the minimum potential energy principle. Bending, shear and geometric stiffness matrix are,

$$
\begin{aligned}
\left|\mathrm{K}_{\mathrm{b}}\right| & =\int_{A}\left|B_{b}\right|^{T}\left|D_{b} \| B_{b}\right| \mathrm{dA} \\
\left|\mathrm{K}_{\mathrm{s}}\right| & =\int_{A}\left|B_{s}\right|^{T}\left|D_{s}\right|\left|B_{s}\right| \mathrm{dA} \\
(7) & \\
\left|\mathrm{K}_{\mathrm{g}}\right| & =\int_{A}\left|B_{g}\right|^{T}\left|D_{g}\right|\left|B_{g}\right| \mathrm{dA}
\end{aligned}
$$


where,

$$
\begin{aligned}
& \left|D_{b}\right|=\left|\begin{array}{cc}
A_{i j} & B_{i j} \\
B_{i j} & D_{i j}
\end{array}\right|, \quad\left|D_{s}\right|=\left|\begin{array}{cc}
K_{1}^{2} A_{44} & 0 \\
0 & K_{2}^{2} A_{55}
\end{array}\right|, \quad\left|D_{g}\right|=\left|\begin{array}{ll}
\bar{N}_{1} & \bar{N}_{12} \\
\bar{N}_{12} & \bar{N}_{2}
\end{array}\right| \\
& \left(A_{i j}, B_{i j}, D_{i j}\right)=\int_{-h / 2}^{h / 2} Q_{i j}\left(1, z, z^{2}\right) d z,(i, j=1,2,6) \\
& \left(A_{44}, A_{55}\right)=\int_{-h / 2}^{h / 2}\left(Q_{44}, Q_{55}\right) d z
\end{aligned}
$$

$D_{b}, D_{s}$ and $D_{g}$ are the bending and shear and geometric parts of the material matrix, respectively. $\mathrm{A}_{45}$ is negligible in comparson with $\mathrm{A}_{44}$ and $\mathrm{A}_{55} . \mathrm{K}_{55}$ represents the shear correction factors for rectangular cross-sections and are given as $\mathrm{k}_{1}^{2}=\mathrm{k}_{2}^{2}=5 / 6$, [9]. In order to obtain system equations, the total potential energy principle is used as follows:

$$
\delta \Pi=\sum \frac{\partial \Pi}{\delta \Delta p} \cdot \delta \Delta p=0
$$

where $\Pi$ is given by,

$$
\Pi=\frac{1 / 2}{2}\{\Delta\}^{\mathrm{T}}\left(\left|\mathrm{K}_{\mathrm{b}}\right|+\left|\mathrm{K}_{\mathrm{s}}\right|+\left|\mathrm{K}_{\mathrm{s}}\right|+\left|\mathrm{K}_{\mathrm{g}}\right|\right)\{\Delta\}={ }_{1 / 2}\{\Delta\}^{\mathrm{T}}\left(\left|K^{*}\right|-\lambda_{\mathrm{b}}\left|K_{b}^{*}\right|\right)\{\Delta\}
$$

where,

$$
|\mathrm{K} *|=\left|\mathrm{K}_{\mathrm{b}}\right|+\left|\mathrm{K}_{\mathrm{s}}\right|-\lambda_{\mathrm{b}}\left|\mathrm{K}_{\mathrm{g}} *\right|=\left|\mathrm{K}_{\mathrm{g}}\right|, \quad \lambda_{\mathrm{b}}=-\frac{\overline{N_{1}}}{N_{1}^{b}}=-\frac{\overline{N_{2}}}{N_{2}^{b}}=-\frac{\overline{N_{12}}}{N_{12}^{b}}
$$

In equation (10), nodal displacements $\left\{\delta_{j}\right\}(\mathrm{j}=1,2,3, \ldots . \mathrm{n})$ have been replaced by the global nodal displacement $\{\Delta\}$ whose number of degrees of freedom is nd. From equations (9) and (10), the following linear algebraic equation is obtained,

$\left(\left|\mathrm{K}^{*}\right|-\lambda_{\mathrm{b}}\left|K_{b}^{*}\right|\{\Delta\} \quad=0\right.$

The critical load $\mathrm{N}_{\mathrm{cr}}$ is obtained from the smallest value eigen $\lambda_{\mathrm{b}}$ determined by the following equation [9],

$\operatorname{Det}\left(\left|K^{*}\right|-\lambda_{\mathrm{b}}\left|K_{g}^{*}\right|\right)=0$ 
Equation (13) is solved by using the iteration technique. In this solution, 228 nodes and 48 nine node plate elements are used.

\section{PRODUCTION OF THE COMPOSITE PLATE}

The composite plate material consists of polyethylene matrix and woven steel fibers. The plastic part of the composite is manufactured in order to satisfy homogeneity in the plate. The thermoplastic is melted by electrical resistance up to $175^{\circ} \mathrm{C}$ in $7 \mathrm{~min}$. And then, the material is held for $5 \mathrm{~min}$. under a pressure of $3 \mathrm{MPa}$ by moulds. Subsequently, the temperature is decreased to $35^{\circ} \mathrm{C}$ under a pressure of $20 \mathrm{MPa}$ in 3 min. Thus, a polyethylene layer is manufactured. The woven steel fibers are put into two polyethylene layers. Subsequently, it is processed in the same way stated above.Thus, composite layer is produced as seen in figure 2.The thickness of a composite layer is $2.2 \mathrm{~mm}$. four layers are bonded by using the same way as defined above. Thus, the total thickness of the composite laminated plate is $8.8 \mathrm{~mm}$ for four layers laminated plate. The mechanical properties and yield strength of the composite layer are measured by using strain indicator. The measured mechanical properties and yield points of a woven reinforced thermoplastic composite layer is given in table 1 .

\section{Table 1. The measured mechanical properties and yield points of a woven} reinforced thermoplastic composite layer.

\begin{tabular}{|c|c|c|c|l|l|l|}
\hline $\begin{array}{c}\mathrm{E}_{1} \\
(\mathrm{MPa})\end{array}$ & $\begin{array}{l}\mathrm{E}_{2} \\
(\mathrm{MPa})\end{array}$ & $\begin{array}{l}\mathrm{G}_{12} \\
(\mathrm{MPa})\end{array}$ & $\boldsymbol{\nu}_{12}$ & $\begin{array}{l}\text { Axial } \\
\text { yield } \\
\text { point } \\
\mathrm{X}(\mathrm{MPa})\end{array}$ & $\begin{array}{l}\text { Transvers } \\
\text { yield } \\
\text { Point } \\
\mathrm{Y}(\mathrm{MPa})\end{array}$ & $\begin{array}{l}\text { Shear } \\
\text { yield } \\
\text { Point } \\
\mathrm{S}(\mathrm{MPa})\end{array}$ \\
\hline 9040 & 9040 & 690 & 0.32 & 16.20 & 16.20 & 7.25 \\
\hline
\end{tabular}

\section{NUMERICAL RESULTS AND DISCUSSIONS}

The plastic composite plates are assumed to be under uniform axial or biaxial in-plane loads along the rectangular edges of the plates as shown in figure 1 . The square hole is free from the loading. They are composed of orthotropic layers bonded symmetrically or antisymmetrically. The plates are simply supported.In all cases, critical loads are calculated using the following equation,

$$
\overline{\mathrm{N}}_{\mathrm{cr}}^{*}=\mathrm{N}_{\mathrm{cr}} \mathrm{b}^{2} / \pi^{2} \mathrm{D}_{22}
$$




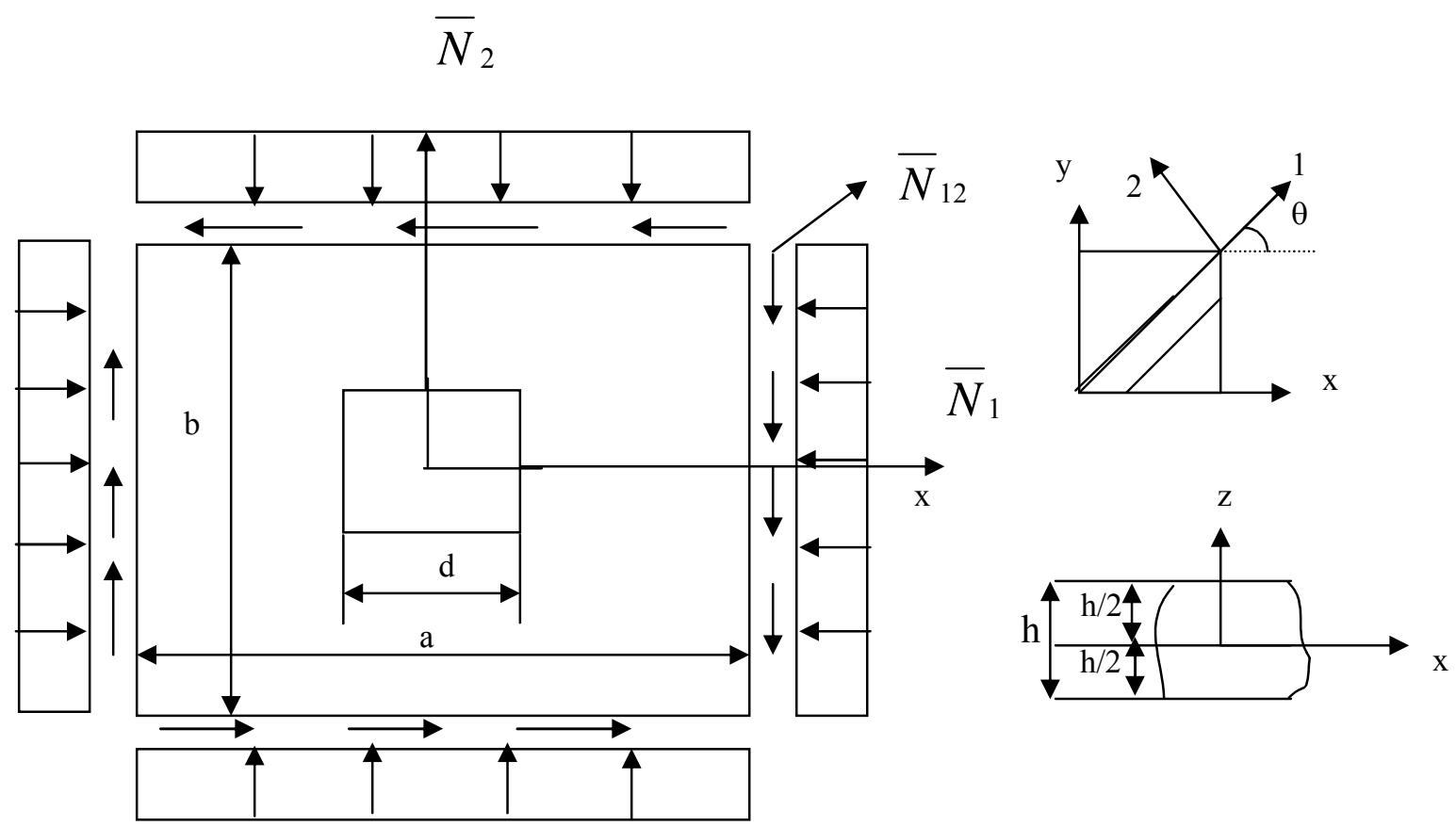

Figure 1.Notch geometry and loading configuration.

the term $\mathrm{N}_{\mathrm{cr}}{ }^{*}$ is the critical load of a composite plate without a hole. The elastic module, shear module and Poisson's ratio of fiber-reinforced composite plates have been determined in terms of the properties of the fibers and the matrix and in terms of the relative volumes of fibers and matrix.It is investigated that influence of square hole on critical loads for antisymmetric cross-ply, $\left(0^{\circ} / 90^{\circ}\right)$ and $\left(\left[0^{\circ} / 90^{\circ}\right]_{3}\right)$ laminated square plates under uniaxial or biaxial compressions are given in figure 3 . for simplysupported and clamped boundary conditions for comparison. It is seen that the influence on critical loads mainly depends upon on hole size and boundary conditions. And addition also seen, the influence of hole size on critical load is more affected for the $\left(\left[0^{\circ} / 90^{\circ}\right]_{3}\right)$ laminated plated. The influence of hole on critical load as a function of thickness ratio $\mathrm{b} / \mathrm{h}$ is given in figure 3 . for $\left(\left[0^{\circ} / 90^{\circ}\right]_{3}\right)$ antisymmetric cross-ply composite plate with simple or clamped edges. In this case, laminated plates have been manufactured at the thickness ratio $h / b=10$ and $h / b=20$ and the laminated plates supported edges under biaxial compressions. $\mathrm{N}_{\text {cr }}^{*}$ is the critical load of the plate without a hole in the ratio of $\overline{N_{c r}} / \mathrm{N}^{*}$ cr. It is seen from figure 4. that thickness ratio of $\mathrm{b} / \mathrm{h}$ is more significant for thinner plate and this influence is more effect for simply supported plate.The results of the influence of the hole and the versus modulus ratio $E_{1} / E_{2}$ for antisymmetric cross-ply simple thermoplastic-matrix composite plates are shown in figure 5.In this case, it is seen from results that the hole effect on critical load is relatively insensitive to modulus ratio $\mathrm{E}_{1} / \mathrm{E}_{2}$. The effect of biaxial loading ratio on critical load of notched composite laminate is presented in figure 6 . In this case, 
laminated composite plate under biaxial compression is more unstable than under compression-tension.

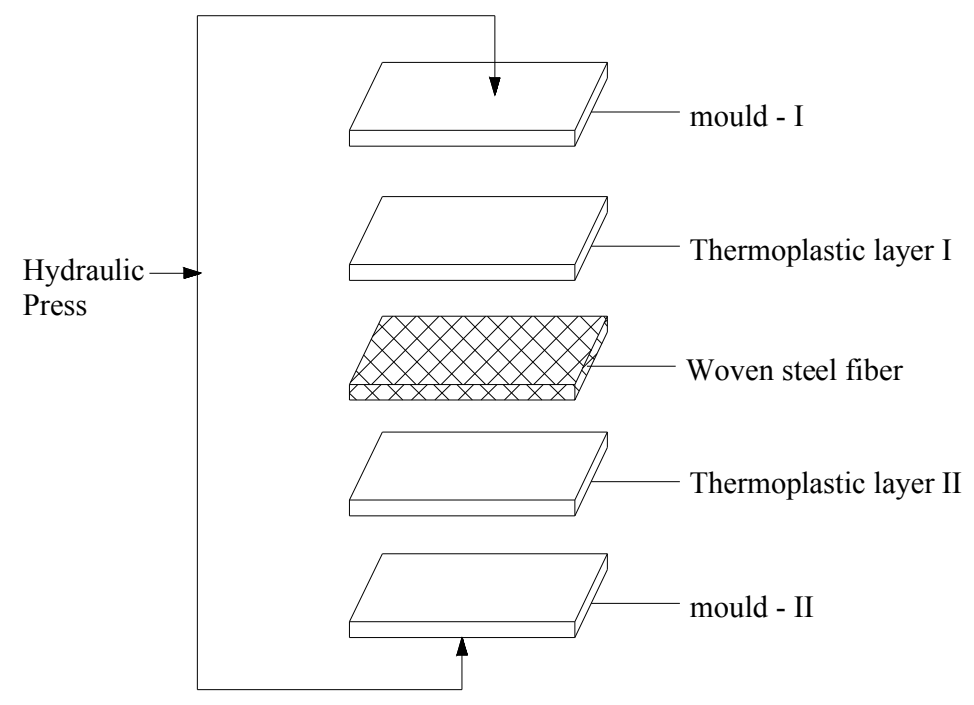

Figure 2. Production of the laminated plate

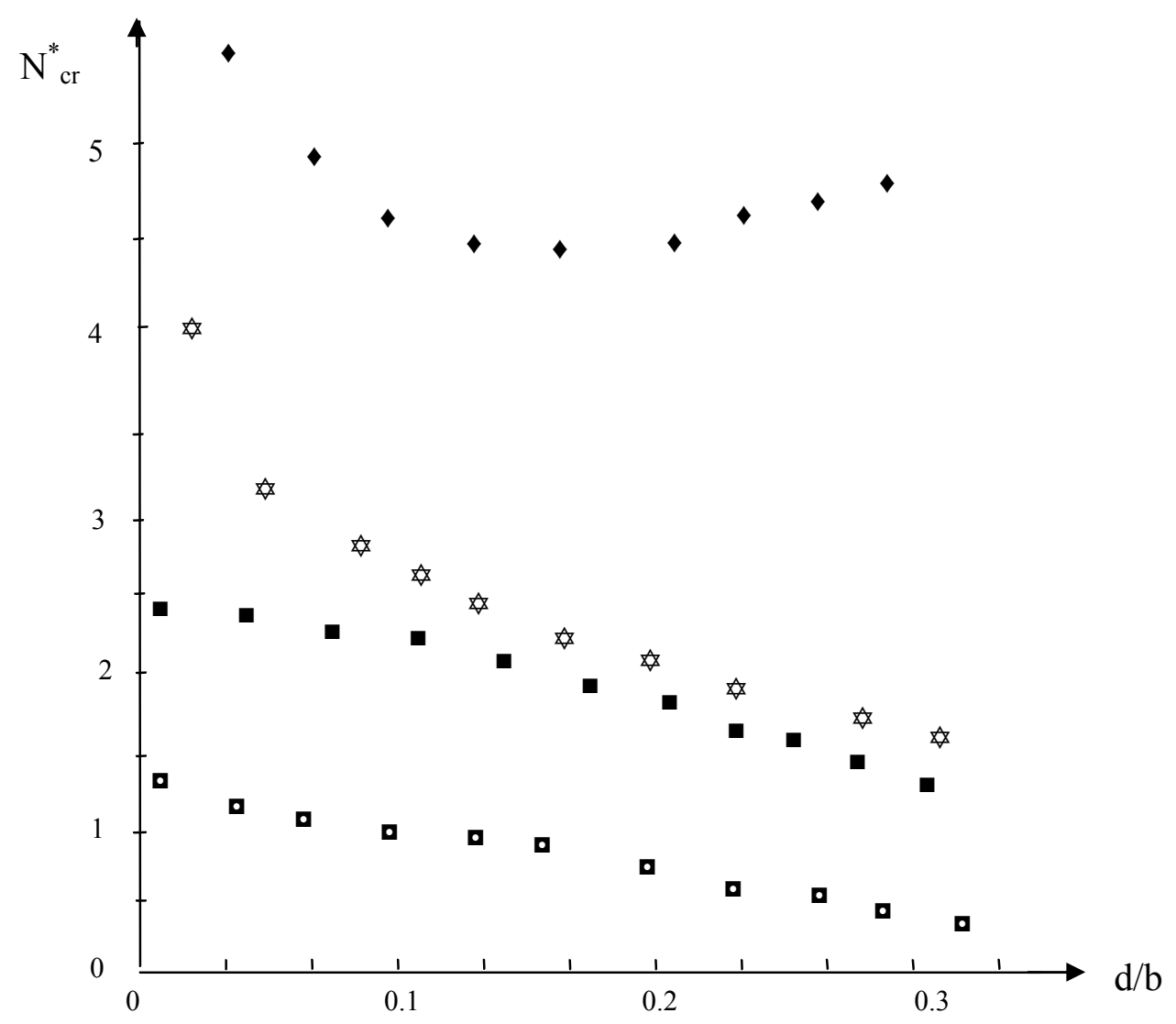

Figure 3. Hole effect on critical loads of $\left(0^{\circ} / 90^{\circ}\right)$ and $\left(\left[0^{\circ} / 90^{\circ}\right]_{3}\right)$ cross-ply laminates. 


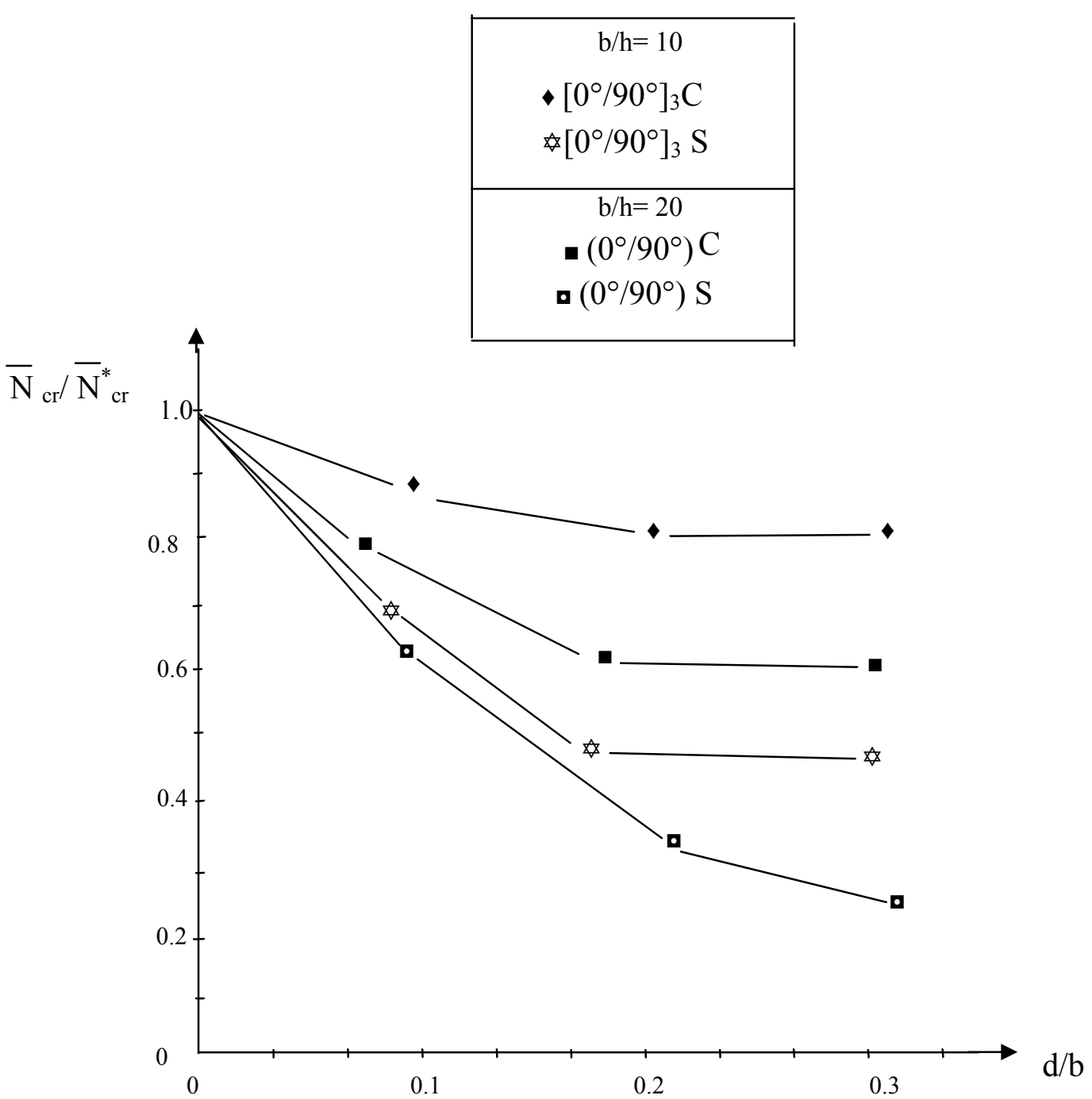

Figure 4. Effect of thickness ratio on critical load of $\left(\left[0^{\circ} / 90^{\circ}\right]_{3}\right)$ cross-ply laminate for $\mathrm{b} / \mathrm{h}=10$ and $\mathrm{b} / \mathrm{h}=20$. (Simply-supported:S and clamped : C ). 


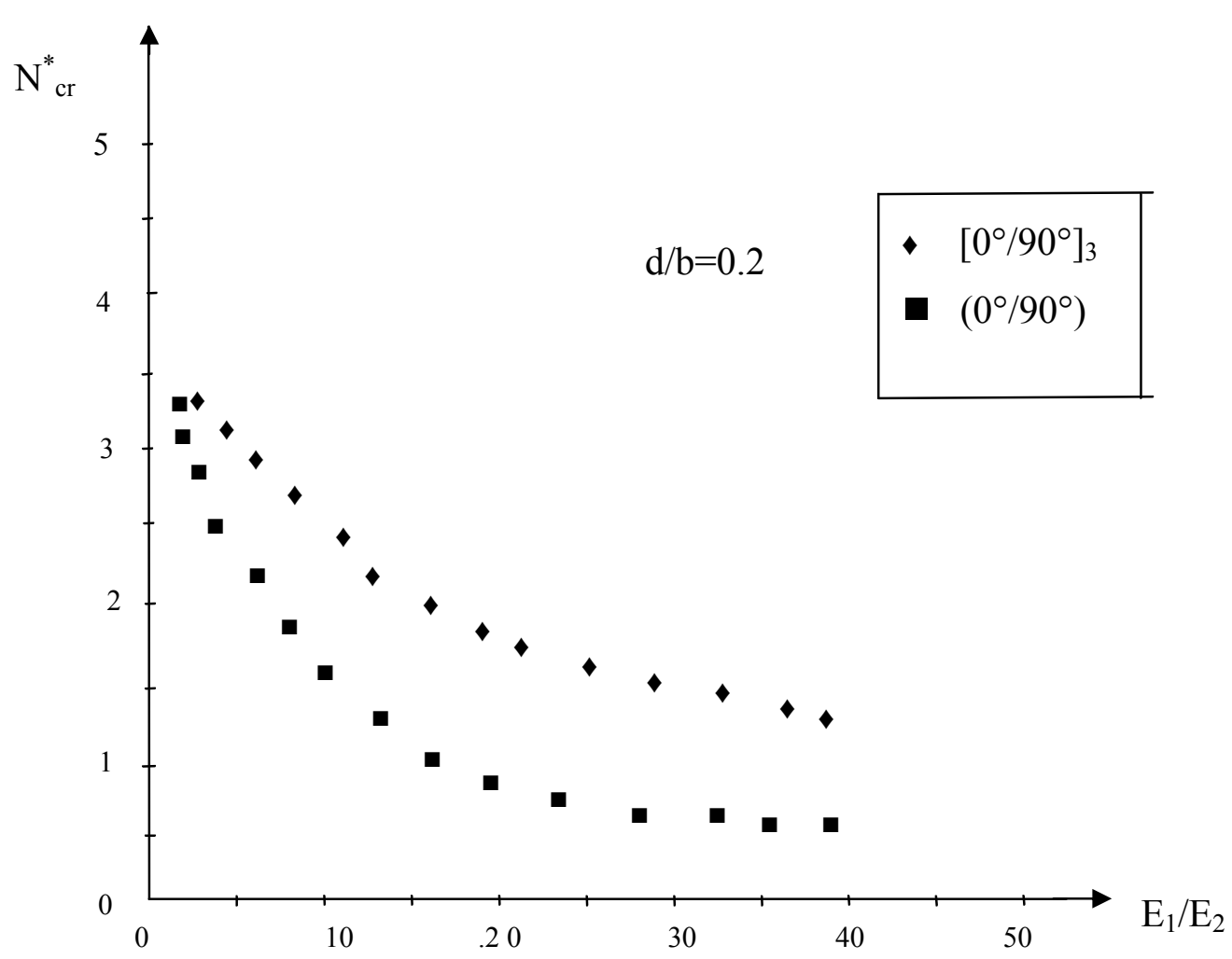

Figure 5. Hole effect on critical load versus modulus ratio for $\left(0^{\circ} / 90^{\circ}\right)$ and $\left(\left[0^{\circ} / 90^{\circ}\right]_{3}\right)$ cross-ply laminate under uniaxial compression.

\section{CONCLUSIONS}

In this study, an investigation of buckling analysis which includes geometric and material effects on critical load of thermoplastic-matrix composite plates with square hole is carried out by using finite element method (FEM). The results can be concluded as below:

1. A significant reduction in the critical load occurs for laminated plate containing a central square hole.

2. The stress concentration for plate containing a large hole is more important than for a plate containing small hole.

3. The reduction in critical load is more effective in uniaxial compression than in biaxial Compression.

4. The effect of critical load of a notched plate is more sensitive for thinner plates.

5. The effect of the modulus ratio $\mathrm{E}_{1} / \mathrm{E}_{2}$ on the critical load of notched composite laminated plate is not as important as on the factors listed above.

6. The reduction in the critical load of metal-matrix composite plate is dependent on the ply orientation $\theta$ for antisymmetric position. If laminated plate is under uniaxial compression, the $\left(\left[45^{\circ} /-45^{\circ}\right]_{\mathrm{N}}\right)$ laminate has the optimum resistance to buckling. 


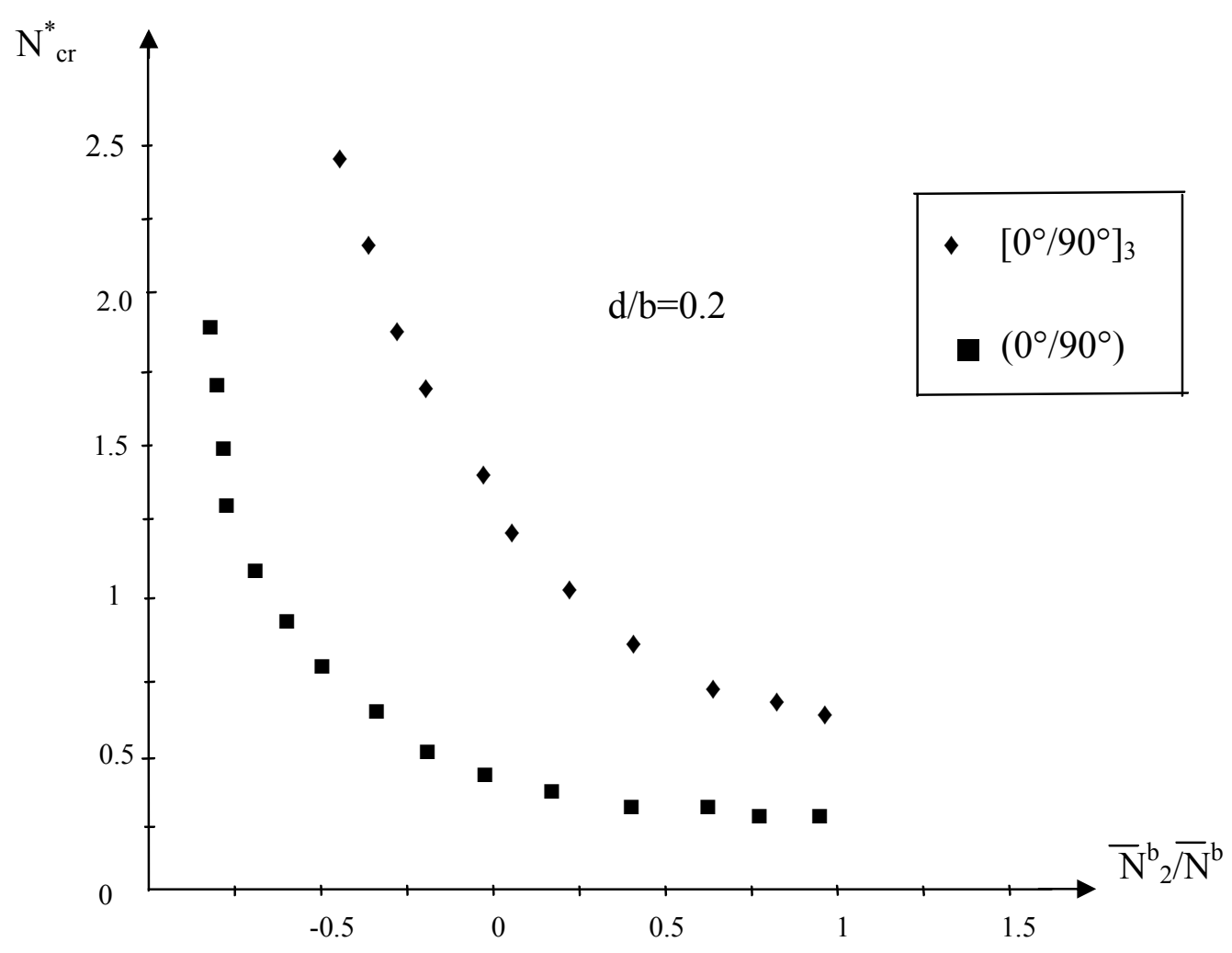

Figure 6. Effect of biaxial loading ratio on critical load of $\left(0^{\circ} / 90^{\circ}\right)$ and $\left(\left[0^{\circ} / 90^{\circ}\right]_{3}\right)$ cross-ply simple square plate.

\section{REFERENCES}

1.FF. Shi, The mechanical properties and deformation of shear induced polymer liquid crystalline fibers in an engineering thermoplastic, Journal of Composite Materials, 30:1266-81,1996.

2.R. Marissen, HR. Brouwer, and J. Linsen, Notched strength of thermoplastic woven fabric composites, Journal of Composite Materials, 29:1544-64,1995.

3. D. Jegley, Impact-damage graphite-thermoplastic trapezoidal corrugation sandwich and semi-sandwich panels, Journal of Composite Materials, 27:526-38,1993.

4. T.P. Murtha, and DG. Brady, High performance composites based on polyphenylence sulfide, 29 th National SAMPE symposium, 1984.

5. D.J. Vanden Brink, and M.P.Kamat, Post-Buckling Response of Isotropic and laminated composite Square Plates With Circular Holes. In proc. Int. Conf. Composite Material. San Diego, Calif., PP.1393-1409,1985.

6.P.L. Larsson, On Buckling of Orthotropic Compressed Plates with Circular Holes, Composite Structures 7, PP. 103-121,1987..

7. M. Uenoya, and R.G. Redwood, Elasto-plastic shear Buckling of Square Plate with Circular Holes, Computers and structures, 8:291-300,1977. 
8. T.W. Chou, A. Kelly, and A.Okura, Fibre-Reinforced Metal-Matrix Composites, Journal of Composite Materials, 16:187-206, 1985.

9. C.R. Ananth, and N.Chandra, Numerical Modeling of Fiber Push-out Test in Metallic and Intermetallic Matrix Composites-Mechanics of the Failure Process, Journal of Composite Materials, 29:1488-1514,1995.

10. R.Pitchumani, P.K.Liaw, S.C.Yao, D.K.Hsu, and H.Jeong, An Eddy CurrentTechnique for the Measurement of Constituent Volume Fractions in a three Phase Metal-Matrix Composite, Journal of Composite Materials, 28:1743-1769, 1994.

11. F.Pomies, and L.A.Carlsson, Analysis of Modulus and Strength of Dry and Wet Thermoset and Thermoplastic Composites Loaded in Transverse Tension, Journal of Composite-Materials, 28:22-35,1994.

12. M.A.Zocher, D.H. Allen, S.E.Groves, and W.W.Feng, Evaluating of First Ply Failure in a Three - Dimensional Load Space, Journal of Composite Materials, 29:1649-1678,1995.

13. C.C. Lin, C.S. Kuo, Buckling of Laminated Plates with Holes, Journal of Composite Materials, 23:536-553,1989. 